\title{
CONSTRUINDO DIÁLOGOS \\ TRANSDISCIPLINARES: DISCUTINDO \\ DIVERSIDADE CULTURAL-HUMANA JOGANDO \\ PETECA
}

\author{
Mirian A. Mateus Gomes ${ }^{1}$ \\ Maria Cristina Bonetti ${ }^{2}$
}

\section{RESUMO}

O Brasil é um país de múltiplas caras, cores e signos, por esse motivo, é constituído de uma pluralidade cultural significativa e expressiva, arraigada de aspectos políticos e econômicos, o que torna sua constituição um processo extremamente complexo, contraditório, dicotomizado e muitas vezes segregador. Em razão desse contexto, nosso trabalho preconiza pela necessidade de conhecermos e valorizarmos a diversidade cultural, principalmente, dos sujeitos inseridos no processo educacional, considerando as influências e interferências das múltiplas nuances culturais existentes, na direção de uma educação complexa capaz de contribuir com o crescimento humano, com uma tomada de consciência ético-política, além da (re)elaboração do conhecimento. O mesmo tem como objetivo discutir o emprego do jogo tradicional de Peteca na perspectiva da Interdisciplinaridade e Transdisciplinaridade, como elemento preponderante na discussão sobre diversidade cultural-humana, ao mesmo tempo em que promove a obtenção do conhecimento em suas múltiplas valências. Apurou-se que o uso de práticas inovadoras, assim como a renovação das práticas educativas tradicionais, comprometidas com a valorização da multiculturalidade, da diversidade humana e cultural, provocam no indivíduo a reelaboração não só de conceitos, mas também dos valores éticos humanos.

PALAVRAS-CHAVE: Prática educativa. Transdisciplinaridade. Diversidade. Cultura. Peteca.

1 Mestranda em Educação pela Universidade Federal de Goiás (UFG). Educadora Social da Secretaria Municipal de Cidadania. Goiânia, GO, Brasil. E-mail: Mirianap013@hotmail.com.

2 Doutora em Ciências da Religião pela PUC-Goiás. Pós-doutora pelo Programa de Pós-Graduação da Faculdade de História da Universidade Federal de Goiás (UFG). Professora na Universidade Estadual de Goiás (UEG). Goiânia e Pirenópolis, GO, Brasil. E-mail: mcbonetti@gmail.com. 


\section{ABSTRACT}

Brazil is a country with multiple faces, colors and signs. For this reason, Brazil is a significant and expressive cultural plurality, rooted in political and economic aspects, which makes its constitution an extremely complex, contradictory, dichotomized and often a segregator. Because of this context, our work advocates the need to know and value the cultural diversity, especially of the subjects inserted in the educational process, considering the influences and interferences of the multiple cultural nuances that exist, towards a complex education capable of contributing to growth human, with an ethical-political awareness, besides the (re) elaboration of knowledge. The purpose of this paper is to discuss the use of Peteca's traditional game in the perspective of Interdisciplinarity and Transdisciplinarity, as a preponderant element in the discussion of cultural-human diversity, while at the same time promoting the acquisition of knowledge in its multiple valences. It was found that the use of innovative practices, as well as the renewal of traditional educational practices, committed to the appreciation of multiculturalism, human and cultural diversity, provoke in the individual the re-elaboration not only of concepts but also of human ethical values.

KEYWORDS: Educational practice. Transdisciplinarity. Diversity. Culture. Peteca.

\section{Introdução}

O Brasil é um país de múltiplas caras, cores e signos, por esse motivo é constituído de uma pluralidade cultural significativa e expressiva, arraigada de aspectos políticos e econômicos, o que torna sua constituição um processo extremamente complexo, contraditório, dicotomizado e muitas vezes segregador. No intuito de modificar esse cenário, o Ministério da Educação e do Desporto, conjuntamente com alguns professores elaboram os Parâmetros Curriculares Nacionais (PCNs), documento que, entre outros elementos, busca contribuir a partir de uma concepção pedagógica crítica na formação de cidadãos participativos, reflexivos e autônomos, cientes de seus direitos e deveres. $\mathrm{O}$ documento reconhece, ainda, que a prática pedagógica 
é complexa principalmente em função da pluralidade cultural brasileira. Ao falar sobre pluralidade e diversidade, o documento aponta que

coexistem aqui culturas singulares, ligadas a identidades de origem de diferentes grupos étnicos e culturais. Essa composição cultural tem se caracterizado por plasticidade e permeabilidade, incorporando em seu cotidiano a criação e recriação das culturas de todos esses povos, sem diluí-las, ao mesmo tempo que permite seu entrelaçamento (BRASIL, 1997, p. 24).

As interconexões culturais e as interferências múltiplas que convivem entre as diversas culturas existentes em nosso território contribuem para a confluência de uma identidade cultural única e complexa em sua constituição e em suas formas de manifestação.

Convivem hoje no território nacional cerca de 206 etnias indígenas, guardando, cada uma delas, identidade própria, representando, em si, riquíssima diversidade sociocultural, além de uma imensa população formada pelos descendentes dos povos africanos e um grupo igualmente numeroso de imigrantes e descendentes de povos originários de diferentes continentes, de diferentes tradições culturais e de diferentes religiões (BRASIL, 1997, p. 24).

Essa diversidade étnica e sociocultural torna nossa nação uma profusão de cores, sabores, rostos e gestos, expressos pela diversidade religiosa, linguística, racial/étnico, cultural. Encontramos facilmente "diferentes características regionais, diferentes manifestações de cosmologias [...], formas diversas de organização social nos diferentes grupos e regiões, multiplicidade de modos de relação com a natureza, de vivência do sagrado e de sua relação com o profano" (BRASIL, 1997, p. 24). Basta darmos uma circulada por qualquer lugar em nosso país para perceber como somos diferentes entre nós, temos uma infinidade de tons de pele, cores e texturas de cabelo, um leque quase interminável de linguagens e sotaques, indiscutivelmente somos um povo ricamente marcado pela diversidade cultural.

Nesta perspectiva, este projeto aponta para a necessidade de se desenvolver no espaço escolar novas práticas que contribuam para a formação de um sujeito multidimensional, multirreferencial 
e auto-eco-organizador, ampliando suas percepções, assim como sua capacidade de análise crítica dos processos sociais, culturais e econômicos imbricados na construção do conhecimento por ele consumido.

Por sua vez, nos apropriamos dos conceitos e dos preceitos da Complexidade e da Transdisciplinaridade, que na prática pedagógica, segundo Nicolescu (1999), representa uma tentativa de superação, assim como a busca de novas ações e práticas que possibilitem a ressignificação de conceitos e fundamentos epistemológicos e objetivos. Tendo ao fim, como objetivo, a compreensão do mundo presente, para o qual um dos imperativos é a unidade do conhecimento. Dessa forma, propomos uma educação que rompa com os processos unicamente formativos, a fim de contribuir para a (re)elaboração de conhecimentos que levem a uma consciência cidadã, humana, ética e solidária.

\section{Os meandros da cultura: o elo preceptor da condição humana}

\section{1- Mas afinal o que é cultura?}

Empiricamente, entendemos cultura como:

Um conjunto de costumes, ...construidos e pensados para os descendentes, ...passados de geração em geração (ENTREVISTADA 1).

É o modo de viver de um povo, os costumes, valores, vestimentas, hábitos (ENTREVISTADA 2).

Cultura é o mundo que criamos para viver; é como nos comunicamos com o mundo e como compreendemos, assimilamos valores, ideias e até mesmo padrões (ENTREVISTADA 3).

Essa nossa forma de percebermos e compreendermos a cultura descrita na fala de nossas entrevistadas não está de todo errada, pois, segundo os PCNs (1997), a cultura compreende um conjunto de códigos simbólicos reconhecíveis por um grupo, a partir 
dos quais os mesmos produzem seu conhecimento; conhecimento que é responsável pela formação do indivíduo, desde sua concepção, passa pela infância e, posteriormente, o introduz na vida adulta concedendo-lhe obrigações sociais para com o grupo e se desdobra por toda sua vida imprimindo-lhe os valores e a maneira como cada grupo social as concebe. Nesse contexto, a cultura, como código simbólico, apresenta-se como dinâmica viva.

Por estar ligada à dinâmica social, a cultura mostra-se em constante processo de reelaboração e introduz paulatinamente na sociedade novos símbolos, valores e hábitos, adaptando-se às necessidades do tempo-espaço. A cultura pode ainda assumir sentido de sobrevivência, estímulo e resistência mediante às mudanças do tempo-espaço. Ao mesmo tempo, apresenta-se como componente indispensável na defesa da individualidade, frente ao pluralismo característico da democracia (BRASIL, 1997).

Segundo Bauman (2012), a cultura funciona como um elo entre o indivíduo humano, o mundo que o cerca e o que ele percebe e elenca enquanto real. Dessa forma, cada sistema, cada indivíduo, cada grupo, a partir de suas escolhas, molda sua forma de ser, de viver, e de se expressar. Essas escolhas, na prática, representam uma função normativa com informações capazes de reduzir ações conflitantes entre membros de um mesmo grupo, ao passo em que promove uma unicidade entre as ações dos mesmos, criando uma relação de interdependência entre os indivíduos daquele grupo, diminuindo assim suas angústias e incertezas, instituindo o que hoje chamamos de "estrutura social". (BAUMAN, 2012)

Podemos afirmar, então, que é por meio da cultura que os indivíduos projetam sua individualidade e subjetividade dentro da coletividade. No entanto, de modo geral, a cultura tem como principal função modelar. Segundo Bauman (2012, p.195), a cultura se objetiva, se torna palpável, observável e se perpetua a partir de suas "formas de abrigo, vestimenta, culinária, bebida, meios de transporte, padrão de lazer, etc". Nesse viés, a cultura, entre outros aspectos, compreenderia as relações sociais e suas várias representações objetivas no mundo material, mas também, suas representações simbólicas, "incluindo características e valores econômicos, técnicas, estruturas políticas, comportamentos étnicosmorais, crenças, formas educativas e criações artísticas" (CUNHA 2010, p. 26). 
Entretanto, esses elementos, ainda que representem um coletivo, uma unicidade, eles estão envoltos de subjetividades, de particularidades, e de individualidades, cada indivíduo escreve e introjecta seu modo de ser, de ver, de sentir nesses elementos, o que torna a cultura um elemento complexo, bem como, contraditória.

\subsection{Diversidade cultural}

A cultura humana, por ser um elemento complexo, contraditório e principalmente rico em subjetividades, apresenta uma gama quase que infinita de representações e de manifestações, vislumbradas por nós por meio de uma diversidade de elementos, símbolos e signos.

A expressão "diversidade" pode representar a compressão e a noção de diferença entre a espécie humana, a constituição física, a diversidade ambiental, assim como a complexa multiplicidade dos elementos constitutivos de nossa sociedade. Em uma perspectiva mais crítica, "diversidade pode ser entendida como um processo de ruptura com o modelo de educação que segrega e exclui aqueles que não se enquadram nos padrões estabelecidos" (REIS e LOPES, 2016, p.154).

Pode ainda, significar "[...] o reconhecimento e o respeito à diferença, à riqueza dos múltiplos olhares e das diversas maneiras de ser e de pensar do ser humano que é complexo e constituído por identidades" (REIS e LOPES, 2016, p.155). Essa visão se aproxima do que entendemos como uma visão holística, uma visão voltada para a coletividade, envolta de uma percepção humana sensível, na qual a essência se faz mais evidente.

Dantas (2014, p. 344) afirma que "diversidade cultural implica diversidade e identidade", para tal, devemos reconhecer a existência de uma sociedade marcada pela diferença e pela diversidade, ou seja, uma sociedade multicultural. Para pensar em uma educação transformadora, complexa e transdisciplinar antes de qualquer coisa, "é preciso romper a visão egocêntrica para pensar no "outro" como possibilidade para construir e estabelecer uma convivência mais harmoniosa pelo exercício da alteridade" (REIS e LOPES, 2016, p.156). Se compreendermos que a diversidade cultural-humana é o que torna nossa sociedade única, e que a mesma está presente nos diversos espaços sociais, como na família, no lazer, e principalmente 
nos espaços escolares, estaremos consequentemente contribuindo com a consolidação de uma sociedade auto-hetero-eco-formativa.

\section{Cultura e educação: uma união feliz na construção do ser complexo}

Compreendendo que o desenvolvimento de uma sociedade está conectado a seus processos culturais, é que apontamos, na sequência, a importância da relação estabelecida direta e indiretamente entre educação e cultura:

[...] a cultura está indissociavelmente ligada à educação, na vertente formal como na vertente não-formal e/ou permanente, e de que esse vínculo assume, em termos históricos, uma assunção política recorrente [...], como, por exemplo: na ação das escolas populares e universidades livres; na construção da cidadania e nas elaborações e reivindicações de direitos e políticas culturais; nas proposições de democratização cultural e, ainda, nas formas de entendimento do multiculturalismo, em cadência com as questões atuais relativas à diversidade, ao respeito e reconhecimento (CUNHA, 2010, p. 10).

A cultura ajuda a construir a educação, assim como o processo educativo constrói e ressalta a cultura e suas representações. Nesse contexto, ao juntarmos as duas, criamos uma infinidade de possibilidades de formação, uma formação pautada em valores mais humanos, conscientes na construção de um mundo mais solidário e coletivo (CUNHA, 2010).

Se a educação é constituída em parte pela cultura, a escola se configura como um espaço sociocultural de encontro das diferenças, assim como o espaço privilegiado de cidadania. Sendo assim, a educação se apresenta como uma ferramenta imprescindível na tarefa de incluir socialmente as pessoas, bem como, de contribuir para o desenvolvimento da personalidade humana, promovendo e viabilizando direitos fundamentais necessários à promoção de uma vida digna, cooperativa, colaborativa e tolerante (PINHO et al, 2015). 
Nesta conjuntura, devemos ensinar conteúdos condizentes com a realidade histórico-social vigente, e que trabalhem a partir da articulação dos saberes fundamentais para a educação do futuro. Dentre estes, os valores sociais, como a diversidade, o respeito mútuo, a indiferença, a compreensão da ética humana e a valorização de toda cultura, sem exclusividade ou rejeição. Na busca da transformação da prática pedagógica, faz-se necessário romper com o tradicional rumo ao novo e, muitas vezes, incerto, além de "buscar novas maneiras de pensar o presente pode nos permitir novas percepções, novas compreensões, novas concepções, novas cosmovisões e, quem sabe, novas possibilidades" (SUANNO, 2015, p. 28). Dessa forma, a Complexidade e a Transdisciplinaridade contribuem na construção de um novo olhar sobre o processo de formação do conhecimento ao religar os vários saberes e conhecimentos, ao articular saberes empíricos e saberes teóricos-científicos, e ao relacionar teoria e prática.

Suanno (2015, p. 263) ressalta que, na perspectiva complexa, ao religarmos os saberes, evidenciamos a práxis ao mesmo tempo em que potencializamos uma compreensão "sistêmica, organizacional e hologramática". Logo, tanto o saber acadêmico-científico quanto o saber empírico-tradicional necessitam ser autoreferenciados de forma autopoiética, a fim de construir sentido e significado na transformação, no conhecimento e na realidade (SUANNO, 2015).

Nesse contexto, destacamos que um processo de ensino-aprendizagem desenvolvido a partir de um pensamento transdisciplinar procura articular os conhecimentos, a fim de construir uma práxis-social sólida, capaz de ampliar nos indivíduos uma noção autocrítica, contribuindo com sua sensibilização social e humana, além de imputar no indivíduo o comprometimento socioambiental para com o planeta (SUANNO, 2015).

\subsection{O brinquedo e a brincadeira: brincar é coisa séria}

Não é segredo para ninguém que brincar é uma atividade muito prazerosa para quem brinca, promove descobertas e estimula a imaginação, além disso, ela ajuda a enriquecer as relações interpessoais, ampliando a sociabilidade entre os envolvidos, ou seja, para a criança, brincar é uma coisa séria, vias de regra, a brincadeira seja espontânea ou direcionada representa um fator preponderante para o desenvolvimento físico, intelectual, bem como social. 
Justamente por ser considerada coisa séria, é que a brincadeira em nosso país é garantida por meio de leis, brincar constitui um direito previsto e assegurado pela LEI N ${ }^{\circ}$ 8.069, DE 13 DE JULHO DE 1990, em seu Art. 16, inciso IV (ECA).

Acreditamos e defendemos a ideia de que o ensino deve ser aberto às experiências culturais inerentes às atividades corporais, orientadas por um processo de coparticipação mediando o conhecimento e a realidade histórico-cultural, respeitando a realidade dos alunos e as competências do professor. Sendo assim, as diversas práticas corporais presentes na sociedade, como as danças, as brincadeiras e os jogos, se apresentam como excelentes possibilidades pedagógicas para trabalhar e para desenvolver as noções históricas da cultura corporal, bem como, trabalhar o sentido lúdico e a criatividade sobre os aspectos do mundo do trabalho e do lazer. Nesse aspecto, enfatizamos que as brincadeiras, os jogos, assim como as danças no contexto escolar;

O homem, historicamente, buscou perpetuar sua história por meio de representações, objetivas (vestimentas, utensílios) e subjetivas (crenças e hábitos), e é nesse contexto de representação cultural que surge o jogo, "o jogo é uma invenção do homem, um ato em que sua intencionalidade e curiosidade resultam num processo criativo para modificar, imaginariamente, a realidade e o presente" (Coletivo de Autores 1992, p. 66).

Através do jogo, podemos viver e alcançar a essência da vida, assim produzir transformações afetivas, psicológicas, sociais, espirituais e motoras. Segundo Brotto (1997), o jogo é mais que uma representação simbólica da vida, ao jogar, o indivíduo pratica direta e indiretamente um exercício de "coexistência de (re)conexão" com a vida, pois o jogo ajuda o indivíduo a desenvolver os aspectos afetivo, psicológico, social, espiritual e motor. Pontuamos, então, que a utilização de formas e de práticas corporais e educativas não convencionais, como o jogo e a brincadeira, no processo de ensinoaprendizagem, pode apresentar elementos constitutivos importantes para uma formação ampla e complexa.

Nesse viés, trabalhar com jogos e brincadeiras, no processo de ensino-aprendizagem, vem ao encontro com os preceitos da Teoria da Complexidade e da Transdisciplinaridade, isso porque, ao contrário da educação tradicional, que prima por uma educação na qual os alunos guardam montanhas e montanhas de conhecimento, distribuídos na escola por disciplinas desligadas e de forma mecânica, 
assim como a complexidade e a transdisciplinaridade, o jogo e brincadeira possuem uma leveza e uma flexibilização invejável e deliciosa, sem perder o compromisso com o educar.

\section{Relato de uma vivência}

Esta proposta de intervenção abordaojogo tradicional dePeteca na perspectiva da Complexidade, da Inter e Transdisciplinaridade, e a sua interconexão simbólica enquanto construção humana que reflete a miscigenação étnica na edificação da cultura popular brasileira. Buscando construir diálogos sobre a diversidade cultural-humana e, ao mesmo tempo, alavancar a obtenção do conhecimento em suas múltiplas valências. A escolha do jogo da Peteca, tido como um jogo tradicional da cultura indígena, se dá a partir da compreensão que essa brincadeira traça intersecções simbólicas importantes para a discussão da diversidade cultural e humana. Apesar de uma linguagem própria e peculiar, a peteca apresenta fatores sociais, econômicos e culturais complexos que influenciam inter e transdisciplinarmente as relações estabelecidas entre a criança e o meio social no qual está inserida.

Nessa perspectiva, a peteca contribuiria na aquisição ou até mesmo na ampliação de conhecimentos disciplinares-formais e conhecimentos informais. O jogo da peteca pode contribuir inter e transdisciplinarmente para uma melhor compreensão corporal, pois ajuda a trabalhar o equilíbrio, a lateralidade, a profundidade e o deslocamento. Pode contribuir, também, para a compreensão de texturas, formas, peso, espessura, parábolas, força em um contexto matemático. Pode ainda estabelecer uma relação com a linguagem quanto à sua origem fonética e escrita. Além dos elementos culturais que aparecem através da geografia, história, artes e da música. Poderíamos pensar todos esses conhecimentos trabalhados isolados, fragmentados, entretanto, ressaltamos que, apesar de suas especificidades, eles estão presentes em um único elemento: a peteca. $\mathrm{O}$ que nos traz de volta a nossa vivência.

Nossa intervenção começa com um questionamento: como trabalhar a diversidade tendo como instrumento pedagógico o jogo e a brincadeira? Daí a escolha do nosso objeto de estudo: a peteca. Sabe-se que os indígenas possuem muitos jogos e brincadeiras, alguns deles são comuns entre os vários povos espalhados pelo 
Brasil e pelo mundo, outros também são comuns entre os não índios, como é o caso da peteca e da perna de pau. Como a cultura indígena possui fortes interconecções com o folclore brasileiro, principalmente por meio dos contos, lendas e estórias passadas de pai para filho, a brincadeira da peteca atravessou gerações, tornandose um elemento folclórico por suas características de: anonimato, tradicionalidade, transmissão oral, conservação, transformação e universalidade, entretanto, a peteca, ainda nos dias atuais, possui uma boa visibilidade, acessibilidade e, principalmente, aceitação.

Segundo informações disponibilizadas no site da Confederação Brasileira de Peteca, não se sabe exatamente quando a peteca surgiu, mas sabe-se que, desde antes do descobrimento do Brasil, ela já era praticada pelos povos nativos do Brasil. A palavra Pe 'teca é de origem Tupi, e significa - bater com a mão, ou bater e se divertir, tradicionalmente, é feita de palha e penas. Sabe-se, ainda, que o jogo era utilizado pelos nativos como atividade esportiva para ganho de aquecimento corporal durante o inverno, como um instrumento de recreação, e também como instrumento ritualístico em festas, sua transmissão e propagação se deram de forma oral, espontânea e intergeracional.

Munidos dessas informações, propomos uma vivência às alunas da segunda turma de Pós-graduação em Transdisciplinaridade e Interdisciplinaridade na Educação ministrado na Universidade Estadual de Goiás-Inhumas, junto à disciplina de Formação Cultural e Estética, ministrada por minha orientadora, Dr ${ }^{\mathrm{a}}$. Maria Cristina Bonette. Demos andamento em nosso trabalho, inicialmente, com uma explanação em sala de aula sobre o entendimento e a conceituação do objeto peteca, buscamos promover a compreensão de sua função e o papel na sociedade indígena e não indígena, sua história, suas aplicações e sua importância. Para então, posteriormente, após abarcarmos o valor e a ligação estabelecida entre o indivíduo e o objeto, partirmos para a confecção propriamente dita da peteca. Para ilustrar o feitio da peteca tradicional, confeccionada com palha de milho e barbante, exibimos um breve filme em sala, o que facilitou a apreensão das colegas para o manuseio do material disponibilizado para a confecção do brinquedo.

Nossa vivência foi realizada no pátio da Universidade Estadual de Goiás, Câmpus Inhumas, com duração de uma hora e meia e contou com a participação de trinta alunas e alunos, na sua maioria, professores das diversas áreas da licenciatura. Inicialmente, 
as pessoas se mostraram curiosas, mas, ao mesmo tempo, receosas quanto à confecção da peteca, tendo em vista que a maioria nunca havia tido contato com o objeto confeccionado da forma tradicional. Apesar de termos dado preferência para a confecção da peteca tradicional feita apenas com a palha do milho, disponibilizamos para as alunas outros materiais diferentes como: corino, T.N.T, E.V.A, penas, brita, caixas de fósforo, tesouras, barbantes e jornal, essa ação embora simples denota o cuidado e o respeito com as particularidades e com a capacidade de aprendizagem e desenvolvimento dos envolvidos no processo, ou, como aponta Moraes (2015, p. 13), “em uma sala de aula, esses níveis de percepção e de compreensão variam muito, bem como os níveis de consciência". Essa ação possibilitou com as alunas explorarem sua criatividade e sua habilidade de forma mais tranquila. A maioria delas preferiu trabalhar com os materiais alternativos disponibilizados, provavelmente, devido à dificuldade encontrada na montagem da peteca tradicional, que, apesar de simples, necessita uma certa habilidade manual.

Durante o desenvolvimento da oficina ou vivência, notamos várias reações, algumas de espanto, outras de ansiedade, algumas de desinteresse, mas, em sua grande maioria, de encantamento e felicidade em produzir e criar algo que teria a sua identidade, seu esforço. Essas sensações e reações podem ser explicadas pela ausência de "consciência" sobre o fenômeno vivenciado. Suanno e Silva (2016, p. 26) explicam a partir de Paul (2013) que o "nível de realidade" de algum fenômeno ou a forma como o indivíduo compreende e lida com algo estão relacionados com o "nível de percepção" e de "pensamento" do sujeito, em contrapartida, essa percepção está concomitantemente associada ao contexto ao qual o indivíduo está inserido. Nesse viés, a falta de vivência produz no indivíduo estranhamento diante do novo ou do diferente.

Passados os estranhamentos, notamos uma grande interação entre as participantes. Enquanto trabalhávamos, observamos uma constante troca de ideias entre elas, nas ações mais difíceis, como o corte do corino (material de couro sintético utilizado como base da peteca), e a amarração. Percebemos a colaboração entre elas, durante a atividade, a todo o momento, elas jogavam e experimentavam a peteca para acertar o peso e a quantidade de penas necessárias para o bom equilíbrio da peteca.

Cremos, ainda, que nossa intervenção seja considerada uma pequena ação diante do complexo processo de produção 
do conhecimento formal. Apontamos um primeiro passo rumo à construção de uma auto-hetero-ecoformação, a partir de uma tomada de consciência que possibilita transformar não somente o indivíduo, mas o induz a perceber a realidade à sua volta, bem como as urgências da coletividade. Nossa vivência promoveu uma autoformação por promover "um sistema de relações pessoais com diferentes pessoas, espaços, culturas, oportunidades, sensibilidades, percepções" (FINGER, 1984 apud, SUANNO e SILVA, 2016, p. 42).

Percepção exemplificada na seguinte fala:

a confecção da "Peteca" possibilita a criação de algo em que "eu” enquanto produtor me perceba naquilo, logo, dou sentido, significado e as minhas características a este objeto. Deste modo, e perante a estas práticas que se tem a busca da reforma do pensamento complexo, que conduz a uma reforma de vida, podendo despertar aspirações no sentido da responsabilidade que cada um de nós tem na construção da formação de um cidadão planetário (ENTREVISTADO 8).

Nossa intervenção foi concluída com a produção de um texto por nossas participantes, um breve relato sobre a vivência e sua relação com uma atuação pedagógica transdisciplinar, pedimos também que ambas relatassem se elas percebiam a existência de uma relação entre cultura e formação educacional. E como a transdisciplinaridade dialogaria com o tema diversidade cultural dentro de um processo de formação?

Para nossas participantes, a cultura aparece como um elemento importante na formação do indivíduo: A cultura tem influência na identidade educacional e humana apresentando-se como componente da vida dos povos (ENTREVISTADA 4). Ou ainda, quando falamos em cultura e formação humana é algo que está intrinsecamente ligado, interligado, pois não é possível desassociá-la. A cultura é algo que constitui o indivíduo sendo responsável pela construção da sua identidade pessoal e profissional (ENTREVISTADA 5).

Essas falas reforçam o que havíamos dito, anteriormente, que não é possível desvincular o indivíduo de sua cultura, nem tampouco, retirar da educação os elementos constitutivos da cultura humana. E é nesse contexto de indissociabilidade que a transdisciplinaridade ganha destaque, uma vez que tal perspectiva 
preconiza a compreensão do todo, das diferenças, do contraditório, do diverso. Essa compreensão fica clara em nossas entrevistas:

A Inter e a Transdisciplinaridade é uma perspectiva que possibilita a ligação com a diversidade cultural no sentido de resgatar a essência do ser, trazendo os aspectos da vida do educando para o processo de formação educacional, dessa forma a diversidade cultural está presente na existência do ser, fazendo parte da sua essência. Dessa maneira, a cultura é uma que contribui na constituição da identidade, perpassa por toda a formação tanto educacional quanto formação humana, por isso é indissociável a vida (ENTREVISTADA 6).

Essa percepção ocorre porque "o conhecimento transdisciplinar associa-se à dinâmica da multiplicidade das dimensões da realidade" (Santos, 2008, p. 75). Por outro lado, sabemos que, para mudar o pensamento de forma definitiva, faz-se necessário modificar a prática, ou, nas palavras de Santos (2008), "essa mudança atitudinal condiciona-se à mudança epistemológica: mudar um determinado conceito exige, por sua vez, mudanças de outros correlacionados". Uma prática educativa Complexa e Transdisciplinar deve, então, potencializar o trabalho coletivo, as relações interpessoais, a sensibilidade, a empatia, as emoções, a corporeidade, em outras palavras, é papel do professor que trabalha sob a égide da transdisciplinaridade envolver o aluno na construção do conhecimento, dando a ele significado e significância. Fato relatado na seguinte fala:

essas experiências foram muito importantes para repensarmos as nossas atitudes e nossa prática docente e nos inspiram a ter uma prática diferenciada com os nossos alunos. A transdisciplinaridade propõe essa integração dos conhecimentos científicos e a cultura popular. Melhor que ver e ouvir falar, é vivenciar essas experiências! (ENTREVISTADA 2).

Acreditamos ser importante introduzir e desenvolver, junto à prática educativa, o estudo das especificidades do cérebro, da mente, assim como da cultura e dos conhecimentos produzidos pelo 
homem, simultaneamente a seus processos (MORIN, 2011). Ou, como aponta nossa entrevistada:

um profissional transdisciplinar, é aquele que reconhece que a formação dos indivíduos envolve a sua formação como ser humano, com um ser planetário, que se reconhece como parte do meio e por isso o respeita e o valoriza. Neste processo, devese considerar a construção de valores, princípios e respeitar o ritmo de cada aluno, bem como levá-los a compreender o ritmo da natureza (estações do ano, plantas e animais) e como isso influencia o nosso meio (ENTREVISTADA 1).

Esse raciocínio se dá porque nossa entrevistada compreende a necessidade de promover um conhecimento que seja capaz de abarcar, ao mesmo tempo, os problemas globais e locais, a fim de compreender as particularidades e as especificidades neles contidas. De forma conjunta, cabe à educação formal apresentar, descrever e ensinar sobre as múltiplas facetas do ser humano, assim como a diversidade cultural existente no mundo, garantindo a preservação, o respeito, e visibilidade da diversidade, bem como da individualidade dos diversos povos e culturas existentes.

Como apontam nossas entrevistadas, é possível promover conhecimento de forma diferente, que propicia ao aluno vivências além do seu repertório e cotidiano e contribui com sua ampliação de consciência, consequentemente, ampliando o respeito, a empatia, o comprometimento consigo mesmo, com o próximo e com a sociedade. Considerando que o estranhamento se dá pela falta de vivência, faz-se urgente promover experiências significativas nos espaços escolares, a fim de criar um espírito de coletividade.

\section{Análises preliminares}

Iniciamos nossa análise apontando mais uma vez que a educação pode e deve ser utilizada como instrumento no processo de formação humana. Esse posicionamento parte do pressuposto de que a educação possui elementos que possibilitam uma maior compreensão de si enquanto indivíduo e, consequentemente, do outro como seu semelhante. A visão de mundo descrita na fala de 
nossas entrevistadas promoveria transformações tanto no plano individual, quanto no plano social-coletivo.

Para tal, defendemos a necessidade de se repensar nossa atuação nos diversos campos da vida, começando pela base que seria a formação humana. Apontamos, portanto, que o uso de práticas inovadoras, assim como a renovação das práticas educativas tradicionais, comprometidas com a valorização da multiculturalidade, da diversidade humana e cultural provocam no indivíduo a reelaboração não só de conceitos, mas também dos valores éticos humanos. Dessa forma, defendemos e compactuamos com a utilização de uma "prática pedagógica que busque a alteridade, a pluralidade cultural na qual todos poderão ser tratados mediante suas necessidades e especificidades" (REIS e LOPES 2016, p.162).

Nesse contexto, acreditamos que nossa proposta veio ao encontro das necessidades e das demandas apontadas anteriormente e, ao mesmo tempo, coaduna com os preceitos do paradigma da Complexidade, da Interdisciplinaridade e Transdisciplinaridade, ao propor práticas simples, como o uso da peteca para discutir a diversidade cultural-humana, mas que representa na realidade uma mudança de paradigma educacional.

Ao sugerirmos tais alterações, estamos, na verdade, propondo a abertura para o diálogo, estamos vislumbrando ações socioeducacionais pautadas pela interculturalidade, pela diversidade humana, assim como pela pluralidade cultural-humana, a fim de valorizar, resgatar e, sobretudo, dar visibilidade aos atores sociais, muitas vezes escamoteados, negligenciados e esquecidos no contexto escolar.

\section{Referências}

BAUMAN, Zygmunt. Ensaios sobre o conceito de cultura. Tradução Carlos Alberto Medeiros. - Rio de Janeiro: Ed. Zahar, 2012.

BRASIL. Estatuto da criança e do adolescente (1990). Estatuto da criança e do adolescente [recurso eletrônico]: Lei n. 8.069, de 13 de julho de 1990, e legislação correlata. - $13^{\mathrm{a}}$ ed. - Brasília: Câmara dos Deputados, Edições Câmara, 2015. Disponível em: <file://C:/Users/User/Downloads/estatuto_crianca_adolescente_13ed.pdf $>$. Acesso em: mar. 2017.

BRASIL. Secretaria de Educação Fundamental. Parâmetros curriculares nacionais: introdução aos parâmetros curriculares nacionais / Secretaria de 
Educação Fundamental. - Brasília: MEC/SEF, 1997. Disponível em: <http:// portal.mec.gov.br/seb/arquivos/pdf/livro01.pdf>. Acesso em: mar. 2017.

BROTTO, Fábio Otuzi. Jogos Cooperativos: se o importante é competir, o fundamental é cooperar! Ed. Re-Novada - Santos, SP: Projeto Cooperação, 1997.

COLETIVO DE AUTORES. Metodologia do Ensino de Educação Física. São Paulo: Cortez, 1992.

CONFEDERAÇÃO BRASILEIRA DE PETECA. Disponível em: $<\underline{\text { http:// }}$ www.cbpeteca.org.br/historia-da-peteca/>. Acessado em: dez. 2016.

CUNHA, Newton. Cultura e ação cultural: uma contribuição a sua história e conceitos. São Paulo: Edições SESC SP, 2010.

DANTAS, Fernando Antonio de Carvalho. Descolonialidade e direitos humanos dos povos indígenas. In: Revista Educação Pública, v.23, n.53/1, p.343-367 (maio/agosto) Cuiabá, 2014.

FREIRE, João Batista. Prefácio. In: SILVA, Pierre Normando Gomes-da (Org.). Oficina de brinquedos e brincadeiras. - Petropolis, RJ: Vozes, 2013.

MORIN, Edgar, 1921- Os sete saberes necessários à educação do futuro. Edgar Morin; tradução de Catarina Eleonora F. da Silva e Jeanne Sawaya; revisão técnica de Edgard de Assis Carvalho. - $2^{\mathrm{a}}$ ed. - São Paulo: Cortez; Brasília, DF: UNESCO, 2011.

NICOLESCU, Basarab. Um novo tipo de conhecimento - transdisciplinaridade. $1^{\mathrm{o}}$ Encontro Catalisador do CETRANS - Escola do Futuro - USP. Itatiba, São Paulo - Brasil: abril de 1999.

PETRAGLIA, Izabel. Educação complexa para uma nova política de civilização. Educar, Curitiba, n. 32, p. 29-41, 2008. Editora UFPR.

PETRELLI, Rodolfo. Fenomenologia: teoria, método e prática. Rodolfo Petrelli. - Goiânia: Ed. da UCG, 2011.

PINHO, Edna Maria Cruz; FERRAZ, Elzimar Pereira Nascimento; PINHO, Maria José de; BRINGMANN, Luiza Oliveira. A escola de mãos dadas com as diferenças: uma experiência de criatividade e colaboração no Sul do Tocantins são apresentados resultados significativo. In. Pinho, Maria José de. Projetos criativos na prática pedagógica: cantar e encantar a aprendizagem. - Maria José de Pinho; Marilza Vanessa Rosa Suanno; João Henrique Suanno (orgs.). - Goiânia: Editora Espaço Acadêmico, 2015. 
PINHO, Maria José de; MORAIS, Maria José da Silva; SOUZA, Kênia Paulino de Queiroz; SOUZA, Marilúcia Abreu Lima; REZENDE, Scheila de Fátima C. Ações criativas na escola de tempo integral Daniel Batista. In. Pinho, Maria José de. Projetos criativos na prática pedagógica: cantar e encantar a aprendizagem. - Maria José de Pinho; Marilza Vanessa Rosa Suanno; João Henrique Suanno (orgs.). - Goiânia: Editora Espaço Acadêmico, 2015.

PINHO, Maria José de; SOUZA, Kênia Paulino de Queiroz; MORAIS, Maria José da Silva; OLIVEIRA, Ludmila Barbosa; LIMA, Maria de Lourdes Abreu. O universo da escola municipal de tempo integral Daniel Batista-Cotextualização. In. Pinho, Maria José de. Projetos criativos na prática pedagógica: cantar e encantar a aprendizagem. - Maria José de Pinho; Marilza Vanessa Rosa Suanno; João Henrique Suanno (orgs.). - Goiânia: Editora Espaço Acadêmico, 2015.

REIS, Marlene Barbosa de Freitas; LOPES, Cristiane Rosa. Educação e Diversidade: uma relação de alteridade nas práticas escolares. In: SUANNO, Marilza Vanessa Rosa; FREITAS, Carla Conti de. Razão sensivel e complexidade na formação de professores: desafios transdisciplinares. Anápolis: Editora UEG, 2016.

SANTOS, Akiko. Complexidade e transdisciplinaridade em educação: cinco princípios para resgatar o elo perdido. Revista Brasileira de Educação v. 13 n. 37 jan./abr. 2008.

SANTOS, Akiko. Didática sob a ótica do pensamento complexo. - Porto Alegre: Sulina, 2010- $2^{\mathrm{a}}$ ed.

SUANNO, João Henrique. Emoção, cognição e corporeidade: os sete saberes necessários à educação do futuro na sala de aula do presente. In: SUANNO, Marilza Vanessa Rosa; FREITAS, Carla Conti de. Razão sensivel e complexidade na formação de professores: desafios transdisciplinares. Anápolis: Editora UEG, 2016.

SUANNO, Marilza Vanessa Rosa; SILVA, Yara Fonseca de Oliveira e. Pesquisa de natureza complexa e transdisciplinar na formação de professores. In: SUANNO, Marilza Vanessa Rosa; FREITAS, Carla Conti de. Razão sensivel e complexidade na formação de professores: desafios transdisciplinares. Anápolis: Editora UEG, 2016.

Recebido para publicação em março de 2018. Aceito para publicação em maio de 2018. 